\title{
LEI MARIA DA PENHA: ANÁLISE CRÍTICA DA CATEGORIA GÊNERO NAS DECISÕES DO TJRS
}

Caroline M. de Oliveira Azeredo ${ }^{1}$

\author{
MARIA DA PENHA LAW: CRITICAL ANALYSIS OF THE \\ GENDER CATEGORY IN THE DECISIONS OF THE COURT \\ OF JUSTICE OF RIO GRANDE DO SUL
}

RESUMO: O presente trabalho contém resultados parciais de pesquisa empírica realizada no TJRS para identificar os critérios de incidência da Lei 11.340/2006. O objetivo deste artigo é apresentar como o conceito de gênero e de violência de gênero é compreendido pelos julgadores, a partir de decisões proferidas pelo TJRS em conflitos de competência e em recursos em sentido estrito, bem como compreender os significados destas decisões. A verificação das decisões judiciais foi efetuada a partir do método de análise de conteúdo. Em todos os casos, o debate está centrado na possibilidade de enquadrar ou não a violência perpetrada contra a mulher na Lei 11.340/2006. Ressalte-se que não há uma direção teórica específica sobre o termo gênero ou o aprofundamento do tema.

Palavras-chave: Gênero. Violência de Gênero. Lei Maria da Penha.
ABSTRACT: The present work contains partial results of empirical research carried out in the court of justice of Rio Grande do Sul to identify the incidence criteria of Law 11.340 / 2006. The objective of this article is to present how the concept of gender and gender violence is understood by the judges, based on decisions rendered by the court oj justice of Rio Grande do Sul in conflicts of competence and resources in the strict sense, as well as to understand the meanings of these decisions. Verification of judgments was made from the contente analysis method. In all cases, the debate is focused on the possibility of frame or not violence in Law 11.340 / 2006. It should be emphasized that there is no specific theoretical direction on the term gender or the deepening of the theme.

Keywords: Gender. Gender Violence. Maria da Penha Law.

\footnotetext{
${ }^{1}$ Mestre em Direito e Sociedade pelo Centro Universitário La Salle - UNILASALLE. Especialista em Direito do Trabalho pelo Centro Universitário Ritter dos Reis - Canoas (2011). Advogada. Analista Jurídico do Núcleo de Prática Jurídica do Curso de Direito e da área de Desenvolvimento Institucional da Universidade La Salle - (UNILASALLE).
} 


\section{INTRODUÇÃO}

O fenômeno da violência de gênero é considerado antigo, contudo, é um tema atual em nossa sociedade, pois podemos constatá-lo em qualquer família, domicílio ou relação íntima de afeto. Por muito tempo, a violência doméstica não recebeu a devida atenção do Estado, com a justificativa de que se tratava de um problema privado.

Para tentar romper com essa cultura de práticas violentas contra a mulher e retirar do espaço doméstico o problema, foi promulgada a Lei Maria da Penha. A Lei Maria da Penha estabelece mecanismos específicos para assistência e proteção da mulher em situação de violência de violência doméstica e familiar, reconhecendo que toda mulher tem direito a uma vida sem violência, discriminação e humilhação.

Trata-se de tema de grande relevância social, pois a violência de gênero no âmbito doméstico e familiar acompanha a sociedade brasileira, e a lei Maria da Penha surge como instrumento para contribuir com a superação de tal quadro e para avançar na proteção das mulheres e na igualdade entre gêneros, sendo resultado de uma conquista importante para a dignidade e para a reparação das injustiças cometidas.

Nesse sentido, este artigo é fruto de pesquisa empírica realizado no TJRS para identificar os critérios de incidência da Lei 11.340/2006. Contudo, o objetivo, neste momento, é apresentar como o conceito de gênero e de violência de gênero é compreendido pelos julgadores, a partir de decisões proferidas pelo TJRS em conflitos de competência e em recursos em sentido estrito, bem como compreender os significados destas decisões.

O trabalho apresenta pesquisa bibliográfica descritiva, com caráter interdisciplinar, recorrendo-se obras não só da área jurídica, mas também da Sociologia, Psicologia e Antropologia, assim como a pesquisa empírica em decisões judiciais do TJRS, que revelou a compreensão dos julgadores sobre o conceito de gênero e de violência de gênero ou, até mesmo, a afinidade que possuem com o tema, a partir da técnica da análise de conteúdo. 


\section{O CONCEITO DE GÊNERO E A LEI MARIA DA PENHA}

Para entender o fenômeno da violência contra a mulher, é necessário falar sobre gênero. O conceito de gênero foi elaborado a partir dos anos setenta, na segunda fase do feminismo, principalmente no campo das ciências sociais, sendo incorporado às diversas correntes feministas. Conforme Scott (1990), o gênero é um elemento constitutivo das relações sociais, fundado nas diferenças percebidas entre os sexos. E, ainda, o gênero é uma primeira maneira de dar significado às relações de poder ${ }^{2}$. Logo, existe uma diferença entre sexo e gênero, sexo é a categoria biológica, e gênero é a expressão culturalmente determinada da diferença sexual.

Scott (1990) refere que o gênero implica quatro elementos relacionados entre si: a) símbolos culturalmente disponíveis, tal como Eva e Maria como símbolo da mulher em nossa sociedade, afirmando o sentido do feminino; b) conceitos normativos, que colocam em evidência interpretações do sentido dos símbolos que tentam limitar e conter as suas possibilidades metafóricas. Tem-se como exemplo as doutrinas políticas/jurídicas que afirmam de forma categoria o sentido do masculino e do feminino, c) Noções políticas, incluindo as instituições e organização sociais na (re)construção do gênero; d) identidade subjetiva, no sentido de que conferências estabelecem distribuições de poder, tornando-se o gênero implicado na concepção e na construção do poder em si.

Para contrapor o argumento da distinção biológica como fundamento das desigualdades, é preciso demonstrar que não são as características sexuais que definem as desigualdades, e sim a forma como essas são representadas ou valorizadas, aquilo que se diz ou se pensa sobre elas que vai constituir, efetivamente, o que é feminino ou masculino. Ademais, para que se compreenda o lugar e as relações de homens e mulheres numa sociedade importa observar não exatamente seus sexos, mas sim tudo o que socialmente se construiu sobre os sexos (LOURO, 2004, p. 21).

\footnotetext{
${ }^{2}$ Scott (1990) assevera que a ênfase colocada sobre o gênero constitui uma dimensão decisiva da organização, da igualdade e desigualdade. As estruturas hierárquicas baseiam-se em compreensões generalizadas da relação pretensamente natural entre o masculino e o feminino. A autora ainda sustenta que o gênero é uma das referências recorrentes pelas quais o poder político foi concebido, legitimado e criticado, pois ele diz respeito à oposição masculino/feminino e fundamenta ao mesmo tempo o seu sentido.
} 
Desse modo, as diferenças entre homens e mulheres não são propriamente as características sexuais, mas a forma com que são construídos socialmente o feminino e o masculino em diferentes sociedades e em diferentes épocas, fomentando as desigualdades. Portanto, é a cultura que proclama, por exemplo, o lar como lugar da mulher, da submissão ao homem. Especificamente, qualquer transgressão da mulher ao papel social feminino e a preponderância do poder masculino, acredita o homem poder agredi-la ${ }^{3}$.

A naturalização das diferenças entre homens e mulheres legitima as desigualdades, podendo torná-las invisíveis. Dessa forma, "a naturalização dos papéis designados às mulheres faz com que se torne invisível a regulação hierárquica dos sentimentos, dos sexos, do uso do dinheiro, do processo de tomada de decisões, ocultando as relações de poder na família" (CARDOSO, 1997, p. 128). Essa naturalização não passa de uma formulação ideológica que serve para justificar os comportamentos sociais de homens e mulheres em determinada sociedade (GROSSI, 1998).

Para Stolke (2004), Judith Butler, em 1990, transforma a teoria feminista, quando inverte a relação de sexo e gênero, constando que o sexo também seria uma construção social. Butler (2012, p. 25) desconstrói o caráter imutável do sexo, da ideia de que o sexo é natural, e afirma que talvez o próprio construto chamado "sexo" seja tão culturalmente construído quanto o gênero. E, ainda, sustenta que "a rigor, talvez o sexo sempre tenha sido gênero, de tal forma que a distinção entre sexo e gênero revela-se absolutamente nenhuma". Assim, Butler (2012) indicava que o sexo não é natural, mas é ele também cultural como o gênero.

[...] O gênero não deve ser meramente concebido como a inscrição cultural de significado num sexo previamente dado (uma concepção jurídica); tem de designar também o aparato mesmo de produção mediante o qual os próprios sexos são estabelecidos (BUTLER, 2012, p. 25).

Dessa forma, ao centrar o estudo da violência contra as mulheres como questão de gênero, compreende-se que gênero é uma construção social e cultural do que é masculino e feminino, por meio de diversas práticas que estão sempre em desenvolvimento. Assim,

\footnotetext{
3 "O homem deve agredir, porque o macho deve dominar a qualquer custo; e a mulher deve suportar agressões de toda ordem, porque seu 'destino' assim o determina". (SAFFIOTI, 2004, p. 85).
} 
trata-se de um conceito variável, que depende de cada sociedade e de cada momento histórico. Além disso, permite compreender que a discriminação e a violência contra a mulher têm uma razão social/cultural e não natural.

Importante observar os fundamentos das desigualdades entre homens e mulheres. Bourdieu sustenta que a ordem social foi influenciada pela subordinação do feminino ao masculino, dominada pela superioridade masculina.

A ordem social funciona como uma imensa máquina simbólica que tende a ratificar a dominação masculina sobre a qual se alicerça: é a divisão social do trabalho, distribuição bastante estrita das atividades atribuídas a cada um dos dois sexos, de seu local, seu momento, seus instrumentos; é a estrutura do espaço, opondo o lugar de assembleia ou de mercado, reservados aos homens, e a casa, às mulheres (BOURDIEU, 2002, p.18).

O mundo social constrói o corpo como realidade sexuada e como depositário de princípios de visão e de divisão sexualizante. A diferença biológica entre o corpo masculino e o corpo feminino pode ser vista como justificativa natural da diferença socialmente construída entre os gêneros e, principalmente, da divisão do trabalho (BOURDIEU, 2002).

Sendo assim, Bourdieu (2002) refere que as relações de dominação e de exploração que estão instituídas entre os gêneros se inscrevem sob a forma de visão e de divisão, que levam a classificar todas as coisas do mundo e todas as práticas em oposições entre o masculino e feminino. Logo, há prevalência da dominação masculina, marcada por essa divisão entre os sexos, que concede primazia aos homens.

O autor coloca-nos que a visão androcêntrica é continuamente legitimada pelas próprias pratica que ela determina, pois suas disposições resultam da incorporação do preconceito desfavorável contra o feminino, que é instituído na ordem das coisas. Portanto, às mulheres só restam confirmar seguidamente esse preconceito (BOURDIEU, 2002).

A partir da categoria gênero, introduzida nos estudos sobre violência contra a mulher, surge uma nova terminologia, qual seja, violência de gênero ${ }^{4}$. Antes de analisar a violência de gênero, Grossi (1998) ressalta que a categoria violência contra a mulher, hoje

\footnotetext{
${ }^{4}$ Izumino (2004) refere que "[...] a partir dos anos 90 a categoria violência de gênero passa a ser utilizada para definir a violência como aquela que é praticada contra a mulher por ela ser mulher, ou seja, como resultado dominação do homem sobre mulher".
} 
de grande acepção no Brasil, passou a fazer parte do senso comum crítico a partir das mobilizações feministas contra o assassinato de mulheres no final dos anos setenta. Em razão das inúmeras denúncias de violência contra a mulher, no âmbito familiar, o termo é usado como sinônimo de violência doméstica.

A partir dessa abordagem, cabe trazer a definição do termo "violência de gênero", frequentemente utilizado como sinônimo de violência contra a mulher e violência doméstica ${ }^{5}$. Apesar da sobreposição existente entre esses conceitos, há especificidades em cada um. A violência de gênero é mais geral. Abrange a violência doméstica e a familiar. Desta forma, para compreensão do tema, aborda-se o conceito de violência de gênero.

[...] uma relação de poder de dominação do homem e de submissão da mulher. Demonstra que os papéis impostos às mulheres e aos homens, consolidados ao longo da história e reforçados pelo patriarcado e sua ideologia, induzem relações violentas entre os sexos e indica que a prática desse tipo de violência não é fruto da natureza, mas sim do processo de socialização das pessoas (TELES; MELO, 2003, p. 18).

Strey (2004) sustenta que embora a violência de gênero possa incidir sobre homens e mulheres, pesquisas demonstram que a mulher é a maior vítima desse tipo de violência, com consequências físicas e psicológicas muito graves. Portanto, a autora entende que a violência seja, quase, sinônimo de violência contra a mulher e violência doméstica e familiar, embora com suas peculiaridades. E, ainda, define violência de gênero como o ato violento em função do gênero a que a pessoa pertence. Portanto, a violência é praticada porque a vítima é mulher ou homem.

A violência contra a mulher é uma das principais expressões da dominação masculina. Ela reforça a ideia de que as mulheres são objetos pertencentes aos homens e que o exercício da agressão e da humilhação é normal. As mulheres são submetidas a uma soma de dominação e exploração.

A dominação-exploração constitui um único fenômeno, apresentado em duas faces. Desta sorte, a base econômica do patriarcado não consiste apenas na intensa discriminação salarial das trabalhadoras, e sua segregação ocupacional e

\footnotetext{
5 No trabalho Juizados Especiais Criminais e a Violência de gênero, Izumino (2005) tece críticas quanto ao modo como a literatura sobre o tema tem utilizado o termo "violência de gênero". A autora aduz que o paradigma do patriarcado deve ser abandonado, pois ele é insuficiente para explicar as mudanças do papeis sociais e do comportamento de muitas mulheres diante da violência. Para Izumino, quando se define violência de gênero como uma relação de dominação patriarcal, o poder das partes segue concebido como algo estático.
} 
em sua marginalização de importantes papeis econômicos e político-deliberativos, mas também no controle de sua sexualidade e, por conseguinte, de sua capacidade reprodutiva. Seja para induzir as mulheres a ter grande número de filhos, seja para convencê-las a controlar a quantidade de nascimentos e o espaço de tempo entre os filhos, o controle está sempre em mãos masculinas, embora elementos femininos possam intermediar e mesmo implementar esses projetos (SAFFIOTI, 2004, p. 106).

Importante observar que a violência de gênero pode ocorrer de forma gradual, iniciando-se por ofensas, humilhações, agressões, até chegar à morte da mulher ${ }^{6}$. É a violência composta por fases ou ciclos. A violência é composta por quatro fases: fase da tensão, fase da agressão, fase do pedido de desculpas ou do apaziguamento e fase da reconciliação ou lua de mel. (HIRIGOYEN, 2006, p. 62).

Nesse contexto, diversos fatores podem contribuir para permanência da mulher em relações violentas, como dependência emocional e econômica e a transmissão das experiências de violência através de gerações. Logo, a resistência da mulher está relacionada a redes de apoio, condição social, raça, história familiar, idade, acesso à informação, dentre outros. Muitas mulheres resistem à violência de várias formas, como tomando iniciativas para serem independentes, negando-se a fazer sexo, recusando obrigações, deixando o lar, dentre outras. (GROSSI; AGUINSKY, 2012).

Para demonstrar a atual situação da violência, cabe citar o mapa da violência 2015 Homicídios de Mulheres no Brasil, gizando-se os seguintes dados: de 1980 a 2013 foram assassinadas no país 106.093 mulheres, quase a metade das mortes ocorreu na última década. O número de vítimas passou de 1.353 mulheres em 1980, para 4.762 em 2013 (WAISELFISZ, 2015).

Segundo o Atlas da Violência 2016, publicado pelo IPEA, treze mulheres são assassinadas por dia no Brasil conforme últimos dados divulgados pelo SIM - Sistema de Informação de Mortalidade, do Ministério da Saúde. No ano de 2014, 4.757 mulheres foram vítimas de mortes por agressão. Os dados da Central do Ligue 180, da Secretaria de Políticas para as Mulheres da Presidência da República, registram que no mesmo ano, de um total de 52.957 denunciantes de violência, $77 \%$ afirmaram ser vítimas semanais de 
agressões, e em $80 \%$ dos casos o agressor tinha vínculo afetivo com a vítima (marido, namorado, ex-companheiro). Ainda, $80 \%$ dessas vítimas possuem filhos, e $64 \%$ destes presenciaram ou também sofreram violência (IPEA, 2016).

Não há uma via única para garantir uma vida sem violência para as mulheres. Para retirar do espaço doméstico o problema e tentar reduzir e erradicar a violência de gênero, foi promulgada a Lei 113.40/2006. A Lei 11.340/2006, conhecida como Lei Maria da Penha, recebeu o apelido em homenagem à biofarmacêutica cearense Maria da Penha Maia Fernandes, que ficou paraplégica em razão da violência doméstica perpetrada por seu ex-marido, ainda na década de 80. Por conta das agressões sofridas, Maria da Penha ficou paraplégica.

A Lei Maria da Penha é resultado de uma mudança na forma de enfrentar o problema da violência doméstica, com importante contribuição das feministas, que constituíram um campo de poder decisivo para a conquista de novos direitos e para criação de políticas públicas. Portanto, ao desconstruir o modo anterior de tratamento legal e ouvir as mulheres nos debates que antecederam a aprovação da Lei 11.340/2006, o feminismo registra a participação política das mulheres como sujeitos na construção desse instrumento legal e sugere uma nova posição de sujeito no direito penal (CAMPOS; CARVALHO, 2011, p. 9).

A partir da criação da lei há um mecanismo para coibir a violência doméstica e familiar contra a mulher, estabelecendo medidas para a prevenção, assistência e proteção das mulheres em situação de violência, tratando o problema de forma integral. Portanto, "a lei se desvincula daquele campo nominado exclusivamente como penal e cria um sistema jurídico autônomo que deve ser regido por regras próprias de interpretação, de aplicação e de execução da lei" (CAMPOS; CARVALHO, 2011).

Classifica-se como uma legislação de 'segunda geração' que atende às recomendações das Nações Unidas para adoção de medidas de proteção e promoção dos direitos das mulheres que extrapolam as ações de justiça criminal, punitivas e restritivas de direitos para os agressores, e promovem o acesso das mulheres ao direito de viver sem violência" (PASINATO, 2015, p. 534). À vista disso, a Lei 11.340/2006 incorpora a perspectiva de gênero e cria medidas protetivas de urgência e juizados especializados. 
Um dos grandes avanços promovidos pela Lei 11.340/2006 foi a criação dos Juizados da Violência Doméstica e Familiar contra a Mulher - JVDFM, afastando a violência doméstica dos Juizados Especiais Criminais. Contudo, como a instalação dos Juizados da Violência Doméstica e Familiar contra a mulher é uma faculdade, enquanto estes não forem estruturados, as varas criminais acumularão as competências cível e criminal para conhecer e julgar as causas decorrentes da violência doméstica, conforme art. 33 da Lei.

A previsão de medidas protetivas de urgência constitui um dos aspectos inovadores. Elas poderão ser concedidas pelo Juiz, a pedido da ofendida e do Ministério Público. A autoridade policial deverá tomar as medidas cabíveis no momento que tomar conhecimento do fato, bem como o Ministério Público tem igual compromisso. Destaca-se as medidas protetivas de afastamento do lar ou lugar de convivência da vítima; proibição de aproximação da ofendida, fixando limite mínimo de distância; proibição de contato com a ofendida e familiares; suspensão de visitas, dentre outros.

A Lei Maria da Penha criou a categoria "violência de gênero" e definiu o conceito de violência doméstica e familiar contra a mulher no art. 50: "qualquer ação ou omissão baseada no gênero que lhe cause morte, lesão, sofrimento físico, sexual ou psicológico e dano moral ou patrimonial". A lei definiu formas de tutela exclusiva para as mulheres em situação de violência e utilizou o termo gênero, que é mencionado outras vezes no texto legal (art. 8우).

O artigo 5o ainda elencou o espaço de abrangência: a) no âmbito da unidade doméstica, compreendida como o espaço de convívio permanente de pessoas, com ou sem vínculo familiar, inclusive as esporadicamente agregadas; b) no âmbito da família, compreendida como a comunidade formada por indivíduos que são ou se consideram aparentados, unidos por laços naturais, por afinidade ou por vontade expressa; c) em qualquer relação íntima de afeto, na qual o agressor conviva ou tenha convivido com a ofendida, independentemente de coabitação. De outro lado, apontou suas formas no artigo 70 (Violência física, psicológica, sexual, patrimonial ou moral) (BRASIL, 2006).

O conceito de comunidade familiar proposto pela Lei é muito amplo. Ele engloba uma variedade de relações existentes no âmbito doméstico e familiar, não se limitando apenas aos conflitos envolvendo relacionamento amoroso. Salienta-se que as pessoas 
podem ter ou não vínculo doméstico e familiar, pois a lei protege também qualquer relação íntima de afeto. Além disso, não há necessidade que o agressor conviva com a vítima, basta que já tenha convivido, independentemente de coabitação. Nesse sentido, a lei abrange maridos, namorados, ex-namorados, ex-maridos, irmãos, pais, tios, avós, sobrinhos, cunhados, enteados, padrastos, dentre outros. O conceito abrange uma variedade de laços de pertencimento no âmbito doméstico (SIMIOMI; CRUZ, 2011).

Nesse aspecto, pode-se definir que a configuração da violência doméstica e familiar contra a mulher depende da presença dos seguintes requisitos: a) a ação ou omissão deve ser contra a mulher; b) deve expressar uma relação de subordinação e dominação baseada no gênero; c) deve causar os resultados previstos, ou seja, morte, lesão, sofrimento físico, sexual ou psicológico e dano moral ou patrimonial; d) deve ser praticada no espaço de abrangência da lei, ou seja, no âmbito da unidade doméstica, da família, ou em qualquer relação íntima de afeto.

Diante de tais requisitos, a lei se aplica à violência de gênero no âmbito doméstico, familiar ou de qualquer relação íntima de afeto. Logo, não se restringe a violência conjugal, porém, também não se estende a qualquer tipo de violência contra a mulher.

Portanto, a Lei Maria da Penha introduziu o conceito de gênero, considerado basilar para interpretação e para o correto enquadramento do caso concreto à norma.

Sendo assim, em razão do histórico de discriminação e de violência sofridos pela mulher, e em face do poder exercido pelo homem, um diploma legal que usa o gênero como critério de diferenciação não é desproporcional, tampouco inconstitucional, como assentou o STF no julgamento da ADI no 4424. Enquanto existir no país desigualdade entre gêneros, há necessidade (e legitimidade) de uma legislação para compensar as diferenças e promover a igualdade.

\section{JURISPRUDÊNCIA DO TJRS: ANÁLISE DA CATEGORIA GÊNERO}

Apresentados os conceitos estruturantes da pesquisa e a análise da legislação específica, parte-se para a apresentação do debate e das principais controvérsias para aplicação da Lei Maria da Penha, tendo em vista a categoria gênero. Para tanto, considera- 
se importante iniciar com o detalhamento da metodologia e dos procedimentos adotados durante a análise dos acórdãos.

Em relação ao universo de análise, a pesquisa jurisprudencial foi realizada no site do Tribunal de Justiça do Estado do Rio Grande do Sul, com os termos "conflito de competência e Lei Maria da Penha", "conflito e doméstica", "incidência da Lei Maria da Penha" identificando decisões no período de 01/07/2012 a 30/06/2014, com vítimas mulheres.

Desta forma, os termos escolhidos abrangeram, dentre vários recursos, os conflitos de competência suscitados pelos operadores de Juizado da Violência Doméstica e Familiar contra a Mulher, Varas Criminais e Juizados Especiais Criminais, bem como decisões em recurso em sentido estrito.

O conflito de competência ocorre quando dois ou mais Juízos se julgam competentes ou incompetentes para atuar em determinado processo. O conflito poderá ser positivo ou negativo ${ }^{7}$. Será positivo quando mais de um Juiz se considerar competente para julgar a causa; será negativo quando um Juiz declina da própria competência e remete os autos para o Juízo que entende ser competente, e este, por sua vez, também se julga incompetente ${ }^{8}$. Conforme artigo 115 do CPP, este conflito pode ser suscitado pelas partes interessadas (autor e ré), pelo órgão do Ministério Público, ou pelos próprios Juízes ou tribunais envolvidos (AVENA, 2014, p. 369).

Por sua vez, o recurso em sentido estrito é interposto, dentre uma das hipóteses, quando o magistrado entender que seu juízo é incompetente para julgar a causa, em razão dos critérios de incidência da lei ${ }^{9}$. Segundo Avena (2014, p. 1210), "o reconhecimento da

\footnotetext{
${ }^{7}$ CPP, art. 113: As questões atinentes à competência resolver-se-ão não só pela exceção própria, como também pelo conflito positivo ou negativo de jurisdição.

${ }^{8} \mathrm{CPP}$, art. 114: Haverá conflito de jurisdição: I - quando duas ou mais autoridades judiciárias se considerarem competentes, ou incompetentes, para conhecer do mesmo fato criminoso

${ }^{9} \mathrm{CPP}$, art. 581. Caberá recurso, no sentido estrito, da decisão, despacho ou sentença:

$[\ldots]$

II - que concluir pela incompetência do juízo;
} 
incompetência do juízo é decisão interlocutória simples, pois não importa em extinção do procedimento, e, sim, na sua remessa ao juízo competente" A parte não satisfeita pode ingressar com o recurso para o Tribunal de Justiça, que deve decidir a questão, definindo o campo de incidência e o local que a ação deve tramitar.

Decidiu-se por delimitar a pesquisa às decisões prolatadas em conflitos de competência e em recurso em sentido estrito pela intenção de verificar as situações de abrangência da Lei Maria da Penha, bem como as tendências jurisprudenciais do Tribunal de Justiça do RS. Para análise dos conflitos, foram observados os discursos jurídicos referentes aos critérios considerados necessários para aplicação da Lei 11.340/2006.

O Tribunal de Justiça do RS foi o escolhido para a pesquisa jurisprudencial por ser o responsável pelo julgamento dos conflitos de competência suscitados pelos juízes e pelos recursos interpostos contra a decisão de incompetência do juízo.

Após a coleta dos dados, foi utilizado o método qualitativo de análise de conteúdo, tendo em vista que a intenção é identificar o sentido do documento e o conteúdo da comunicação, baseado na proposta de Laurence Bardin (2011).

Bardin (2011) sustenta que a análise de conteúdo é um conjunto de técnicas de análise das comunicações, adaptável a um campo de aplicação muito vasto, como entrevistas, manuais escolares, discursos políticos, manuais escolares, grafites públicos, novelas, dentre outros. Assim, a técnica procura investigar o conteúdo das comunicações (mensagens), não apenas das palavras em si, mas das ideias, do sentido.

Em tese, a análise de acórdão é facilitada pelo dever de fundamentação, inerente à decisão judicial, conforme artigo 93, IX, da Constituição Federal, assim como pela estrutura formal, relatório, discussão e dispositivo.

De acordo com as decisões analisadas, pode-se dizer que elas não possuem grande extensão, mas o conteúdo encontrado apresenta dados importantes em relação aos critérios utilizados pelo ordenamento jurídico para se estabelecer a abrangência do conceito de violência doméstica e familiar contra a mulher, fazendo incidir as disposições da Lei Maria da Penha. 
Pode-se afirmar, de plano, que há divergências no sentido de definir os parâmetros para configuração da violência doméstica e familiar contra a mulher e, em consequência, definir o âmbito competente para o julgamento.

Ainda que a Lei 11.340/2006 seja a aparentemente clara no que se refere à qual âmbito do judiciário é competente para administrar os conflitos familiares por ela abarcados, a prática dos operadores da justiça gaúcha apresenta diferentes interpretações sobre que âmbito do sistema de justiça deve ser responsável pela administração dos conflitos vividos em família e tipificados como referente aos citados na Lei Maria da Penha. A "clareza" da letra da lei parece ser ofuscada a partir do momento em que é reconhecida a possibilidade de interpretação elástica de uma norma jurídica e que, em conseqüência de tal elasticidade, um mesmo conflito pode ser interpretado de diferentes formas" (VASCONCELLOS, 2013, p. 147).

Nessa perspectiva, percebe-se o relevante papel dos Magistrados. Boaventura de Souza Santos afirma que para concretização do projeto político-jurídico de refundação democrática da justiça, é necessário mudar completamente o ensino e a formação de todos operadores de direito, considerando a formação permanente a mais importante

Na Alemanha, não há nenhuma inovação legislativa sem que os Juízes sejam submetidos a curso de formação para poderem aplicar a nova lei. O pressuposto é que, se não houver uma formação específica, a lei obviamente não será bem aplicada. Temos que formar os profissionais para complexidade, para os novos desafios, para os novos riscos. As novas gerações vão viver numa sociedade que, como eu dizia, combina uma aspiração democrática muito forte com uma consciência da desigualdade social bastante sólida. E, mais do que isso, uma consciência complexa, feita da dupla aspiração de igualdade e de respeito da diferença (SANTOS, 2011, p. 82).

Santos (2011) sustenta que a formação da faculdade é uma formação genérica, que deve ser complementada com formações especializadas. Na formação dos magistrados, os estágios devem ser feitos em ONGS, fábricas, movimentos sociais, não apenas em Tribunais ou prisões. A interdisciplinaridade é importante para que o juiz possa decidir adequadamente as novas questões complexas, que exigem mais conhecimentos de outras áreas do que jurídicos.

Eis o que dispõe a legislação para configuração da violência doméstica familiar contra a mulher e aplicação da lei.

Art. 5o Para os efeitos desta Lei, configura violência doméstica e familiar contra a mulher qualquer ação ou omissão baseada no gênero que lhe cause morte, lesão, sofrimento físico, sexual ou psicológico e dano moral ou patrimonial: 
I - no âmbito da unidade doméstica, compreendida como o espaço de convívio permanente de pessoas, com ou sem vínculo familiar, inclusive as esporadicamente agregadas;

II - no âmbito da família, compreendida como a comunidade formada por indivíduos que são ou se consideram aparentados, unidos por laços naturais, por afinidade ou por vontade expressa;

III - em qualquer relação íntima de afeto, na qual o agressor conviva ou tenha convivido com a ofendida, independentemente de coabitação.

Parágrafo único. As relações pessoais enunciadas neste artigo independem de orientação sexual. (BRASIL, 2006).

Com efeito, o artigo 5으 estabelece as condições a serem observadas para que fique configurada a violência doméstica e familiar contra a mulher, incidindo a lei em referência, com a categoria gênero compondo o seu núcleo estruturante.

Portanto, neste momento, passa-se para a análise de conteúdo dos acórdãos a partir da categoria gênero. Considerando que o presente artigo se trata de recorte de uma pesquisa mais abrangente, decidiu-se delimitar o presente trabalho às decisões prolatadas em conflitos de competência e em recursos em sentido estrito que demonstraram como o conceito de gênero e violência de gênero é compreendido pelos julgadores ou, até mesmo, a afinidade que possuem com o tema.

Inicialmente, cabe destacar que o conceito de gênero foi citado somente em um dos acórdãos. Apesar de alguns votos mencionarem, nas decisões TJRS, "motivação de gênero", submissão "em razão de gênero" e "relação de gênero", conclui-se que não há como identificar o que o julgador entende por tais expressões. Destacam-se alguns exemplos.

Em um episódio de agressão de irmão contra irmã, o Desembargador julgou procedente o conflito para declarar a competência do Juizado Especial Criminal, pois não identificou submissão em razão do gênero e o conflito seria cunho familiar e patrimonial, não fazendo incidir a lei especial.

Não identifico, na espécie, a submissão da vítima frente ao agressor em razão de gênero, ou mesmo, situação de vulnerabililidade, hipossufiência e inferioridade física ou econômica. O conflito estabelecido entre eles, ao que tudo indica - a vítima informa que discutiu com seu irmão em razão de pendengas envolvendo os fios da rede elétrica, ele crendo que é o dono da rede, cortou os fios de luz de sua residência; o suposto agressor negando a imputação, dizendo que foi ele quem comprou os fios e que sua irmã cede energia elétrica a outras pessoas, o que dá ensejo a quedas de luz - é de cunho familiar e patrimonial e, no caso concreto, 
não faz incidir a lei especial. Além disso, eles não residem na mesma residência, apenas próximo (RIO GRANDE DO SUL, 2014).

Em outro caso envolvendo tia e sobrinho, o relator entendeu pela não aplicação da Lei Maria da Penha por não evidenciar qualquer saliência da categoria gênero. Observe-se o trecho da decisão.

No caso dos autos, contudo, as suspeitas que recaem sobre a recorrida não revelam prevalecimento de relações de gênero apenas porque ocorreram em ambiente familiar. Em outras palavras, o fato de a vítima ser do sexo feminino não foi decisivo para a prática do delito [...] De todo modo, embora punível o ato praticado pelo acusado, do que se denota das declarações não há qualquer saliência da categoria 'gênero' embutida na relação entre as envolvidas. Ordinariamente, gênero seria a categoria que marca as distinções entre o feminino e o masculino, no campo social, distinguindo-se do 'sexo' (RIO GRANDE DO SUL, 2013a).

No julgamento de um processo envolvendo filha agressora e genitora como uma das vítimas, o julgador entendeu pela aplicação da Lei Maria da Penha, tendo em vista a identificação da submissão em razão de gênero.

[...] que se esteja a tratar de hipótese de violência doméstica e familiar contra a mulher, pois identifico, na espécie, a submissão da vítima mulher frente a agressora, em razão de gênero, sua vulnerabililidade, hipossuficiência e inferioridade física. Basta ver o teor do registro de ocorrência policial de f. 09, o qual consigna que a ofendida - genitora de LUCIANA - reiteradamente vem sendo ameaçada de morte por ela, em razão de transtornos psíquicos manifestados pela ofensora (RIO GRANDE DO SUL, 2013b).

Em outro julgado, em um conflito entre irmão e irmã, o relator sustenta que:

Se enquadra perfeitamente dentro da competência prevista pela Lei n.ㅇ 11.340/06, por ser considerada 'violência doméstica ou familiar contra a mulher'. Entende também que 'não cabe verificar a ocorrência de 'opressão ao gênero' decorrente de condição de hipossuficiência e/ou vulnerabilidade em relação ao agressor, porquanto é vedado ao intérprete distinguir quando a lei não o faz (RIO GRANDE DO SUL, 2013c).

As decisões limitam-se a informar se o julgador identifica ou não identifica, na espécie, a motivação de gênero, a submissão em razão de gênero ou a relação de gênero. Não há maiores esclarecimentos sobre esse entendimento. Além disso, não há uma direção teórica específica ou aprofundamento do tema. Contudo, embora não mencionem 
o entendimento acerca da categoria, mostram que ele está bastante conectado com a ideia de hipossuficiência, vulnerabilidade, inferioridade física.

Importante destacar que a Exposição de Motivos da Lei Maria da Penha requer especial atenção ao conceito de relação de gênero.

\begin{abstract}
O artigo 5o da proposta de Projeto de Lei define violência doméstica e familiar contra a mulher como qualquer ação ou conduta baseada na relação de gênero, que cause morte, dano ou sofrimento físico, sexual ou psicológico. É importante ressaltar que a Convenção de Belém do Pará possui objeto mais amplo, considerando a violência ocorrida no âmbito público e privado. Para os fins desta proposta, e de forma a conferir-Ihe maior especificidade, somente foi considerada a violência ocorrida no âmbito privado. Cabe especial atenção a um conceito basilar previsto na proposta: a relação de gênero. A violência intrafamiliar expressa dinâmicas de poder e afeto, nas quais estão presentes relações de subordinação e dominação. As desigualdades de gênero entre homens e mulheres advêm de uma construção sociocultural que não encontra respaldo nas diferenças biológicas dadas pela natureza. Um sistema de dominação passa a considerar natural uma desigualdade socialmente construída, campo fértil para atos de discriminação e violência que se 'naturalizam' e se incorporam ao cotidiano de milhares de mulheres. As relações e o espaço intrafamiliares foram historicamente interpretados como restritos e privados, proporcionando a complacência e a impunidade (EM nº 016 - SPM/PR).
\end{abstract}

Quando se trabalha com a categoria gênero, deve-se ter em conta as perspectivas lançadas no primeiro capítulo desse trabalho, percebendo as diferenças e as desigualdades entre homens e mulheres como construções sociais e culturais que historicamente privilegiam o poder e a dominação do homem e a submissão da mulher.

Para Montenegro (2015), a violência doméstica contra a mulher constitui-se de um conflito de gênero, portanto, esse conflito deve ser analisado como uma relação de poder entre o gênero masculino representado socialmente como forte, e o gênero feminino representado como fraco.

Além disso, é preciso associar a origem da violência contra a mulher a partir de uma cultura machista que reforça as hierarquias entre o feminino e o masculino. Pretende-se, dessa forma, recolocar o debate no campo social, pois é nele que se constroem e se reproduzem as relações (desiguais) entre os sujeitos. As justificativas para as desigualdades precisariam ser buscadas não nas diferenças biológicas (se é que mesmo essas podem ser compreendidas fora de sua constituição social), mas sim nos arranjos 
sociais, na história, nas condições de acesso aos recursos da sociedade, nas formas de representação (LOURO, 2004, p. 22).

A utilização e compreensão do termo gênero permitem uma análise das diferenças para além do plano biológico, apontando para as construções sociais sobre homens e mulheres, de como devem ser, comportar-se, pensar, desempenhar papeis, que variam em cada período e em cada sociedade, passível, portanto, de mudança ao longo do tempo. Não se trata de negar a biologia, mas enfatizar a construção social e histórica produzida sobre as características biológicas (LOURO, 2004).

Sendo assim, a lei utiliza o conceito de relação de gênero para abordar essa divisão de papeis construída socialmente, estabelecendo-se relações de dominação e subordinação, no qual o feminino tem a função social de ser subordinado ao masculino. Em razão da preponderância do poder masculino, ou, até mesmo, por qualquer transgressão da mulher ao seu papel social, o homem acredita que pode fazer uso da violência.

A partir da categoria gênero surge outra importante questão, a violência de gênero. Ela pode atingir homens e mulheres, mas, as mulheres são, de longe, as mais atingidas. É uma violência, portanto, em função do gênero ao qual a pessoa pertence. A violência de gênero já pressupõe relações de poder, nas quais, historicamente, existe prevalência de um sexo sobre outro (STREY, 2012).

Da mesma forma que o conceito de gênero, a utilização do termo violência de gênero, nas decisões, não indicou com clareza o entendimento do julgador na aplicação do conceito ou os referenciais teóricos sobre os quais fundamenta a decisão.

\section{CONCLUSÃO}

Este artigo analisou como o conceito de gênero e de violência de gênero é compreendido pelos julgadores, a partir de decisões proferidas pelo TJRS em conflitos de competência e em recursos em sentido estrito, bem como os significados destas decisões.

O gênero foi utilizado como categoria de análise, apontando para a construção social e cultural do que é masculino e feminino, através de diversas práticas que estão 
sempre em desenvolvimento. Portanto, trata-se de um conceito variável, que depende de cada sociedade e de cada momento histórico.

A partir dessa análise inicial, focou-se a Lei Maria da Penha, principalmente em relação a análise do conceito de gênero para aplicação da Lei 11,340/2006. Para tanto, analisaram-se as decisões das Câmaras Criminais do TJRS em conflitos de competência e em recursos em sentido estrito, que definiam a incidência ou não da Lei Maria da Penha.

À vista das decisões analisadas, pode-se dizer que elas não possuem grande extensão, mas o conteúdo encontrado apresenta dados importantes em relação ao critério da idade, que foi utilizado pelos julgadores para fazer incidir ou não as disposições da Lei Maria da Penha. Em todos os casos, o debate estava centrado na possibilidade de enquadrar ou não a violência na Lei 11.340/2006.

Observou-se que as decisões se limitam a informar se o julgador identifica ou não identifica, na espécie, a motivação de gênero, a submissão em razão de gênero ou a relação de gênero. Não há maiores esclarecimentos sobre esse entendimento, tampouco uma direção teórica específica ou aprofundamento do tema. Entretanto, verifica-se que o entendimento do conceito de gênero está conectado com a ideia de hipossuficiência, vulnerabilidade, inferioridade física.

Da mesma forma que o conceito de gênero, a utilização do termo violência de gênero, nas decisões, não indicou com clareza o entendimento do julgador na aplicação do conceito ou os referenciais teóricos sobre os quais fundamenta a decisão.

Nesse contexto, há necessidade de um novo olhar sobre a violência doméstica e familiar contra a mulher e sobre os papeis masculinos e femininos, incorporando a perspectiva de gênero e sua relação com a violência. Os estudos de gênero devem ganhar espaço no sistema de justiça, principalmente em função da Lei Maria da Penha, que torna o local propício para essa reflexão, inclusive pelas exigências pragmáticas. 


\section{REFERÊNCIAS}

AVENA, Norberto Cláudio Pâncaro. Processo penal esquematizado. 6. ed. rev., atual. e ampl. São Paulo: Método, 2014.

BARDIN, Laurence. Análise de conteúdo. Ed. rev. e ampl. São Paulo: Ed. 70, 2011.

BUTLER, Judith. Problemas de gênero: feminismo e subversão da identidade. Rio de Janeiro: Civilização Brasileira, 2012.

BOURDIEU, Pierre. A dominação masculina. 2. ed. Rio de Janeiro: Bertrand Brasil, 2002.

BRASIL. Constituição Federal, Código Penal e Código de Processo Penal. 16. ed. Atual. Editora: Revistas dos Tribunais, 2014.

. Lei no 11.340/2006, de 07 de agosto de 2006. Disponível em: <http://www.planalto.gov.br/ccivil_03/_Ato2004-2006/2006/Lei/L11340.htm>: Acesso em: 31 out. 2013.

CAMPOS, Carmen Hein de; CARVALHO, Salo. Tensões atuais entre a criminologia feminista e a criminologia crítica: a experiência brasileira. In: CAMPOS, Carmen Hein de (Org). Lei Maria da Penha comentada em uma perspectiva jurídico-feminista. Rio de Janeiro: Lumen juris, 2011.

CARDOSO, Nara Maria Batista. Mulher e maus-tratos. In: STREY, Marlene Neves (Org.). Mulher, estudos de gênero. São Leopoldo: Unisinos, 1997. p. 127-138.

GROSSI, Miriam. Rimando amor e dor: reflexões sobre a violência no vínculo afetivoconjugal. In: PEDRO, Joana Maria; GROSSI, Miriam Pillar (Org.). Masculino, feminino, plural: gênero na interdisciplinariedade. Florianópolis: Mulheres, 1998b. p. 293-313.

GROSSI, Patrícia Krieger; AGUINSKY. Beatriz Gershenson. Por uma nova ótica e uma nova ética na abordagem da violência contra mulheres nas relações conjugais. In: GROSSI, Patricia K.; WERBA; Graziela (Orgs.). Violências e gênero: coisas que a gente não gostaria de saber. Porto Alegre: Edipucrs, 2012. p. 25-50.

HIRIGOYEN, Marie-France. A violência no casal: da coação psicológica à agressão física. Rio de Janeiro: Bertrand, 2006.

IZUMINO, Wânia Pasinato. Justiça para todos: juizados especiais criminais e a violência de gênero. Tese (Doutorado) - Departamento de Sociologia, Universidade de São Paulo, São Paulo, 2003. Disponível em: <http://www.pagu.unicamp.br/pf-pagu/publicfiles/arquivo/130_izumino_wania_pasinato_termo.pdf>. Acesso em: 11 maio 2015.

. Delegacias de defesa da mulher e juizados especiais criminais: mulheres, violência e acesso à Justiça. Plural: Revista do Programa de Pós-Graduação em Sociologia, v. 12, p. 79-104, 2005.

INSTITUTO DE PESQUISA APLICADA. Disponível em: http://www.ipea.gov.br/portal/images/stories/PDFs/nota_tecnica/160322_nt_17_atlas_d a_violencia_2016_finalizado.pdf?. Acesso em: 24 de jul. 2017. 
LOURO, Guacira Lopes. Gênero, sexualidade e educação: uma perspectiva pós estruturalista. 7. ed. Petropólis: Vozes, 2004.

MONTEnegro, Marilia. Lei Maria da Penha: uma análise criminológico-crítica. Rio de Janeiro: Revan, 2015.

PASINATO, Wânia. Oito anos de Lei Maria da Penha. Entre avanços, obstáculos e desafios. Revista Estudos feministas, Florianópolis, v. 23, n. 2, p. 533-545, maio/ago. 2015.

RIO GRANDE DO SUL. Tribunal de Justiça. Conflito de Competência no 70057005811. Sexta Câmara Criminal. Relator: Icaro Carvalho de Bem Osório. Porto Alegre, 2013a. Disponível em: <www.tjrs.jus.br>. Acesso em: 17 ago. 2015.

. Tribunal de Justiça. Conflito de Competência no 70054635800. Terceira Câmara Criminal. Relator: João Batista Marques Tovo. Porto Alegre, 2013b. Disponível em: <www.tjrs.jus.br>. Acesso em: 10 ago. 2015.

. Tribunal de Justiça. Conflito de Competência no 70054819701. Primeira Câmara Criminal. Relatora: Osnilda Pisa. Porto Alegre, 2013c. Disponível em: <www.tjrs.jus.br>. Acesso em: 02 ago. 2015.

. Tribunal de Justiça. Conflito de Competência no 70057809485. Terceira Câmara Criminal. Relator: João Batista Marques Tovo. Porto Alegre, 2014. Disponível em: <www.tjrs.jus.br>. Acesso em: 10 ago. 2015.

SAFFIOTI, Heleieth I. B. Gênero, patriarcado, violência. São Paulo: Fundação Perseu Abramo, 2004.

SANTOS, Boaventura de Sousa. Para uma revolução democrática da Justiça. 3. ed. São Paulo: Cortez, 2011.

SIMIONI, Fabiane; CRUZ, Fabiane. Da violência doméstica e familiar - artigo 5․ In: CAMPOS, Carmen Hein de (Org.). Lei Maria da Penha comentada em uma perspectiva jurídico-feminista. Rio de Janeiro: Lumen juris, 2011.

STOLKE, Verena. La mujer es puro cuento: la cultura del género. Rev. Estud. Fem, v. 12, n. 2, maio./ago. 2004.

STREY, Marlene Neves. Violência de gênero: uma questão complexa e interminável. In: STREY, Marlene N.; AZAMBUJA, Mariana P. Ruwer; JAEGER, Fernanda Pires (Org.) Violência, gênero e políticas públicas. Porto Alegre, EDUPUCRS, 2004. p. 13-44.

SCOTT, Joan Wallach. Gênero: uma categoria útil de análise histórica. Educação e Realidade, Porto Alegre, 1990.

TELES, Maria Amélia de Almeida; MELO, Mônica de. $\mathbf{O}$ que é violência contra a mulher. São Paulo: Brasiliense, 2003. (Coleção Primeiros Passos).

VASCONCELLOS, Fernanda Bestetti. A família, a violência e a justiça: conflitos violentos familiares, Lei Maria da Penha e concepções jurídicas no Tribunal de Justiça do Rio Grande do Sul. Civitas: Revista de Ciências Sociais, v. 13, p. 136-153, 2013. 
WAISELFISZ, Julio Jacobo. Homicídio de mulheres no Brasil. Mapa da Violência 2015. Disponível em: <http://www.mapadaviolencia.org.br/pdf2015/MapaViolencia_2015_ mulheres.pdf.>. Acesso em: 19 de abr. 2016.

AZEREDO, Caroline Machado de Oliveira. Lei Maria da

Penha: Análise crítica da categoria gênero nas decisões do TJRS. RBSD - Revista Brasileira de Sociologia do Direito, v. 5, n. 2, p. 174-194, mai./ago. 2018. 